\title{
Questions of Legitimacy in Probation Practice after Transforming
} Rehabilitation

Deering, John; Feilzer, Martina

\section{Howard Journal of Criminal Justice}

DOI:

10.1111/hojo. 12200

Published: 01/06/2017

Peer reviewed version

Cyswllt i'r cyhoeddiad / Link to publication

Dyfyniad o'r fersiwn a gyhoeddwyd / Citation for published version (APA):

Deering, J., \& Feilzer, M. (2017). Questions of Legitimacy in Probation Practice after Transforming Rehabilitation. Howard Journal of Criminal Justice, 56(2), 158-175.

https://doi.org/10.1111/hojo.12200

\footnotetext{
Hawliau Cyffredinol / General rights

Copyright and moral rights for the publications made accessible in the public portal are retained by the authors and/or other copyright owners and it is a condition of accessing publications that users recognise and abide by the legal requirements associated with these rights.

- Users may download and print one copy of any publication from the public portal for the purpose of private study or research.

- You may not further distribute the material or use it for any profit-making activity or commercial gain

- You may freely distribute the URL identifying the publication in the public portal ?
}

Take down policy

If you believe that this document breaches copyright please contact us providing details, and we will remove access to the work immediately and investigate your claim. 


\section{Questions of legitimacy in probation practice after Transforming Rehabilitation}

In this article, we discuss the impact of changes to the organisational structure of probation on the legitimacy of probation practice. In particular, we explore how the division of probation into the National Probation Service and Community Rehabilitation Companies could affect the self-legitimacy felt by probation practitioners in both organisations and the implications for probation of a possible lack of overall legitimacy post-Transforming Rehabilitation. This article is based on empirical research exploring the views of probation staff of the (then) impending changes introduced via Transforming Rehabilitation and reflections on what has happened since.

Introduction

'Probation' practice in various statutory and earlier voluntary forms has existed for well over 100 years in England and Wales and has, along with its governance, changed dramatically over this time from its origins in the Police Court missionary and Temperance movements. This is perhaps unsurprising for a service that has had to respond to changing political and policy demands, as well as changes in the nature of crime patterns, sentencing policy, and the characteristics of those under its supervision. Moreover, in recent decades, there is no doubt that public services and service provision generally have had to adapt to social, economic, political, and policy changes. As a result of these macro-level changes, probation has recently experienced its most dramatic organisational restructuring to date and the subsequent implications of these changes for the legitimacy of probation practice is the focus of this article. 
In 2014, under the Transforming Rehabilitation (TR) changes (Ministry of Justice 2013) probation trusts were split into the National Probation Service (NPS) which became part of the civil service and 21 Community Rehabilitation Companies (CRCs) which were subject to marketisation and a commercial tendering process. After the bidding process was completed in 2014, 11 CRCs were owned by private sector companies leading a partnership with third sector organisations; three were joint ventures between the private, public and third sectors; three were a public, private and third sector partnership; two were owned by the private sector exclusively; and another two were equity joint ventures between the private and third sectors (XXX 2015: 13).

The privatisation of criminal justice services raises fundamental questions about the ethics of private companies making profits from crime, victimisation, and punishment. Additionally, there are empirical questions about the effect of privatisation on notions of legitimacy - for example, in what ways might probation services delivered by the private and third sectors be regarded as legitimate in the eyes of different groups (those supervised by probation staff, other criminal justice practitioners, probation staff themselves and the public)? In brief, legitimacy may be seen to have three sub-categories: external legitimacy which considers the extent to which those individuals and groups not affected by an organisation see its activities as legitimate (in this case, the views of the public and other criminal justice agencies); internal legitimacy, the extent to which those subject to its practice see it as legitimate (in this case probation supervisees); self-legitimacy, the extent to which those within an organisation (in this case probation staff themselves) see it as legitimate (Bradford and Quinton 2014). This article aims to consider all three types, but has a particular 
focus upon the impact of recent structural changes on the self-legitimacy of probation practitioners.

Legitimacy and probation

Clearly the changes imposed as a result of TR have had the potential to affect all three types of legitimacy, but perhaps particularly upon self-legitimacy. In a recent major ethnographic study looking at the formation of a CRC from the inside, Robinson et al. (2016) studied staff identity during this time of considerable change. They identified a number of themes: separation and loss, status anxiety, loyalty and trust and liberation and innovation, but concluded that the notion of 'liminality' - of being caught in transition between the old and the new - the 'public and the outsourced', was the most fundamental and important theme (Robinson et al. 2016: 161). Some staff found the emerging CRC to be 'socially invisible' without a clear identity, and in danger of being seen as little more than 'second class probation' (Robinson et al. 2016: 173). Moreover, their previous identity within the 'honourable profession' of probation seemed under some strain due to fears that perceived private sector values and priorities might 'taint' the profession. Robinson et al. (2016:174175) concluded that identities within the CRCs were likely to be liminal for some time until practitioners came to a settled idea of how they might fit (or not) within the world of the CRC. In turn, such an impact may have an effect on the extent to which practitioners might come to see their role as legitimate, but why might this and the wider issue of legitimacy be important? 
Research by Kirton and Guillaume (2015) on the impact of restructuring on both the CRCs and the NPS suggests that Robinson et al's findings may apply equally in the NPS. Kirton and Guillame argue that staff feel that TR has de-professionalised the service and that stress levels are high, due to higher workloads, job insecurity, less autonomy and reduced opportunities for training and progression. Many respondents in their study were considering leaving the service. Moreover, responses to the Ministry of Justice's Civil Service People Survey 2016 for the NPS suggest that only a minoirty of NPS staff feel that they are involved in decisions that affect their work (38\%); that poor performance is dealt with effectively in their team (35\%); that there are learning and development opportunities (42\%); and career opportunities in the NPS (33\%). The vast majority of respondents did not feel adequately rewarded by pay and benefitsii and the majority of respondents were dissatisfied with the management of the NPS, in particular in relation to changes - only $9 \%$ of respondents felt that changes made in the NPS are usually for the better and $16 \%$ that change in the NPS is managed well.

External and internal legitimacy may be seen to be important, because 'when citizens recognize the legitimacy of an authority they believe that the authority has the right to prescribe and enforce law-abiding behaviour' (Murphy et al. 2015: 4). Complementing this, Beetham (1991) contends that legitimacy is multi-dimensional, consisting of three levels. At a procedural level, power relations are set up in adherence to existing laws. At a perceptual level, the laws themselves are justified by reference to the values and beliefs shared by those in positions of dominance as well as subordinates - external legitimacy. Finally, there is evidence of consent with instructions and expressions of power through actions by subordinates, i.e. those subject to the exercise of power - internal legitimacy. So legitimacy 
can be divided into objective criteria such as procedural adherence to laws and political decision making and perceptual ones, the perception of legitimacy by a number of audiences.

Clearly, the changes to probation have procedural legitimacy or legal validity in Beetham's sense in that legislation - the Offender Management Act 2007, supported by the Offender Rehabilitation Act 2014 - was passed by parliament to allow for the new structural arrangements implemented in 2014. However, at a perceptual level, namely, the extent to which an authority is perceived to be 'entitled to be deferred to and obeyed' (Sunshine and Tyler 2003: 513) and expresses shared values and shared moral positions (Hough et al. 2010: 4) a legitimacy deficit may be emerging. Perceptual legitimacy has been considered quite widely in a number of criminal justice sectors (see for example, Crawford and Hucklesby 2013; Genders 2002; Jackson et al. 2010), usually in terms of internal legitimacy and external legitimacy, and it is this legitimacy which may require legitimation activity. Perceptual legitimacy and expressions of consent by those subjected to expressions of power and coercion, probation supervisees in this instance, is not automatic and may be made more likely and reinforced by an active process of 'legitimation work' by those who are empowered to carry out such roles on behalf of the state (Ugelvik 2016). In turn, such 'legitimation work' is likely to be underpinned by practitioners' notions of self-legitimacy.

Moving to the consideration of the importance of self-legitimacy, we argue that in order to carry out legitimation work and to bolster wider legitimacy, those who act as agents of the state need to be convinced of their own legitimacy. This is clearly important in terms of the wider reputation of probation within criminal justice and with the public, but also may be seen to be so in terms of levels of compliance with orders and post-custody licences 
(McNeill and Robinson 2013; Bottoms 2001). Moreover, it has been argued that selflegitimacy increases the chance of criminal justice representatives behaving in a procedurally just manner towards those subjected to their powers and thus increase rates of willing compliance with the law, law enforcement, and punishment (Bradford and Quinton 2014; Murphy et al. 2015). Establishing legitimacy in practitioner-client relationships is based on 'a dialogue [...] by and through which legitimacy [of the police] is established and reproduced' (Bradford and Quinton 2014: 1027). This dialogue is at the core of the contention that the relationship between practitioner and supervisee is the "key site or resource within which to develop legitimacy' (McNeill and Robinson 2013: 122).

Self-legitimacy was defined by Bradford and Quinton (2014: 1026) in relation to police officers' confidence in their own authority and a sense that 'their role and activity [...] is justifiable'. Whilst this has emerged as an area of interest in the policing literature (for example, see Bradford and Quinton 2014; Hough et al 2010; Sunshine and Tyler 2003), in other criminal justice occupations, legitimacy and in particular, self-legitimacy has been explored to a lesser extent. In one study, writing about immigration detention officers in Norway, Ugelvik (2016) discusses the 'backstage self-legitimation work' undertaken by detention officers and discusses the narratives that officers used to bolster self-legitimacy in light of a perceived external legitimacy deficit. A few studies have considered the impact of perceptions of legitimacy upon probation practice and compliance with probation requirements (Hucklesby 2013; McNeill and Robinson 2013). However, there is little discussion of how changes to probation may have affected practitioners' sense of selflegitimacy and how, in turn this may have a long term corrosive effect upon probation practice and its wider legitimacy. 
Bradford and Quinton (2014) suggest that it is possible to measure self-legitimacy through 'respondents' confidence in their own authority and their sense that they occupy a special position in society' (Bradford and Quinton 2014: 1032) and Van Craen (2015) expands this notion by exploring the role of police officers' trust in their supervisors. Of particular relevance in view of recent changes in probation, one further important factor of selflegitimacy was the extent to which police officers feel that they are enabled and supported by their organisation and that they internalise the values represented by their organisation and identify with the organisation (Bradford and Quinton 2014: 1028).

The notion of self-legitimacy has been developed in relation to other criminal justice practitioners, but we are of the view that it also lends itself to the study of probation practice. In this regard, the question we raise is whether recent changes to the organisational set up of probation threaten aspects of the legitimacy of probation services, including, importantly, the sense of self-legitimacy felt by probation practitioners. This is, in our view likely to have a long term impact on the 'success' of community sentences and post-custody licences with significant ramifications for criminal justice overall.

\section{The Study}

This article is based upon the results of an online survey conducted with probation practitioners in March and April 2014 (for a full analysis see XXX 2015). The survey was wideranging and intended to investigate the views of respondents about the forthcoming (at that time) division of the National Probation Service for England and Wales into the NPS and the CRCs. The survey was distributed online via the probation union and professional association, 
Napo and a relatively small number of probation trusts. Many of the trusts appeared reluctant to pass the survey URL on to their staff, presumably due the political sensitivity of the topic and it is acknowledged that the survey sample was non-randomised and self-selecting and thus non-representative and skewed to some degree. However, over 1300 staff of various grades, including managers completed the survey and this represented around 10 per cent of probation staffiii at the time. Whilst we do not make claims for representativeness, we feel that the survey's results are based on a significant degree of staff opinion and raise some concerns as to the future legitimacy of probation practice across the NPS and the CRCs. We also acknowledge that our original survey was conducted in a difficult period in which Napo had conducted a campaign against TR. However, we did receive a minority of responses via probation trusts and have aimed to interpret the responses received in a balanced manner.

Details of the sample:

\begin{tabular}{|c|c|c|c|}
\hline Variable & $\begin{array}{l}\text { Proportion of the } \\
\text { sample, \% }\end{array}$ & $\begin{array}{l}\text { Proportion of the } \\
\text { sample, } \%\end{array}$ & $\begin{array}{l}\text { Proportion of the } \\
\text { sample, \% }\end{array}$ \\
\hline Gender & $65 \%$ female & $35 \%$ male & \\
\hline $\begin{array}{l}\text { Years of work in } \\
\text { probation service }\end{array}$ & $\begin{array}{l}13 \% \text { Fewer than } 7 \\
\text { years }\end{array}$ & $67 \%$ over 10 years & \\
\hline Role in probation & $\begin{array}{l}53 \% \quad \text { probation } \\
\text { officers }\end{array}$ & $\begin{array}{l}23 \% \text { probation service } \\
\text { officers }\end{array}$ & \\
\hline Manager & $\begin{array}{l}15 \% \quad \text { probation } \\
\text { managers }\end{array}$ & & \\
\hline Qualification & $\begin{array}{l}31 \% \text { Diploma in } \\
\text { Probation Studies }\end{array}$ & $\begin{array}{l}24 \% \text { Probation } \\
\text { Qualifications } \\
\text { Framework }\end{array}$ & $\begin{array}{l}15 \% \text { Certificate } \\
\text { in Social Work }\end{array}$ \\
\hline
\end{tabular}


As mentioned in our original study, one of the striking features of the survey is the homogeneity of responses, despite the varied nature of the sample as a whole. The number of statistically significantly differences between sub-groups, divided by gender, grade and age, etc., was small, being limited to different perceptions of the level to which probation was underpinned by agreed values, a perception that offender supervision needed to be more flexible, plus other small differences (XX 2015, 6).

Our original survey and the data collected focused on the values of probation and the (then) forthcoming changes to the ownership of probation services. At the time, respondents were not yet aware which part of the new structures they would belong to. Although not specifically focused on legitimacy, it included questions on internal legitimacy - how probation supervisees might respond to the changes - and questions about who in the respondents' views should be delivering probation services - external legitimacy. We also asked about respondents' views of working within the new organisations and we have used the responses to consider self-legitimacy by drawing on Bradford and Quinton's (2014) work and what they describe as the 'correlates' of self-legitimacy, which seem to us relevant to probation in its current organisational set-up.

As mentioned above, in brief, Bradford and Quinton argue that police officers' notions of self-legitimacy correlated with the extent to which they positively identified with the organisation and felt supported by it (Bradford and Quinton 2014: 1023-1024). Furthermore, a shared group identity is also seen as a component of self-legitimacy. In our survey, this was investigated by questions related to shared values and an occupational culture committed to welfare oriented approaches and a strong belief in people's ability to change (Grant 2016: 
751; Worrall and Mawby 2014: 347). At this point, it is worth noting that respondents' views about legitimacy within the coming NPS and CRCs needs to be tempered by a finding within our earlier study that respondents had felt that the values and practices of the public probation service had been coming under pressure from government for some years prior to our survey. More details can be found in XXX (2015) where respondents did indicate that manysome of the things that they feared from TR (for example a more managerialist and less rehabilitative approach to practice) and had previously started to happen and, in that way TR was a continuation of government policy since the creation of NOMS in 2004, which paved the way for TR. However, although seen as a continuing trajectory, respondents seemed to feel that TR would exacerbate these issues.

Our sample responded to both closed and open ended questions and thus data were received in both quantitative and qualitative formats. The use of Likert scales allowed 'sound bite' responses to be compared to more considered qualitative responses - we received a wealth of detailed commentary to the open ended questions. Moreover, responses made clear references to the impact of the impending changes on professional practice, a shared set of values for probation, and fragmentation between NPS and CRC practices.

\section{Probation practitioners' views of Transforming Rehabilitation and questions of legitimacy}

Our survey posed questions concerning probation values; why respondents had joined the service; whether it had lived up to expectations; who should do probation work; what it should consist of; what the private and third sectors might bring to probation work. Many of 
the responses resonated strongly with aspects of legitimacy set out above and their expectations of the difficulty of legitimation activity in the future. Responses reflected practitioners' liminal state (Robinson et al., 2016) and their expectations and concerns about moving to work within either the CRCs or the NPS. We have analysed responses to a range of questions based loosely on elements of Bradford and Quinton's (2014: 1028-1029) correlates of self-legitimacy as well as the importance of narrative legitimation work (Ugelvik 2016) and have considered respondents' professional values; their attachment to either the NPS or the CRC; the internalisation of organisational goals; a sense of being supported by the organisation; and a belief that practitioners are legitimate holders of authority.

A considerable amount of research has pointed to the perseverance and resilience of probation values; the notion that probation practitioners share a common set of values and principles. These can be summarised as a desire to make a difference and having faith in people's ability to change (Grant 2016; Deering 2011; Mawby and Worrall 2013). Responses to our survey concerning probation values clearly related to why people had chosen to join the service. The main reasons were related to a desire to work with people who had experienced difficulties that underlay their offending. Respondents had a clear belief in an individual's ability to change and in the role of the probation service in potentially assisting that process. The work of the service was seen as attractive because it was felt to be primarily rehabilitative and transformative, although clearly within the context of risk assessment and management and the protection of the public. This context of risk was, however, qualified to some degree. Risk assessment was regarded as important, but it tended to form the context for working with people to overcome problems and hence change their behaviour; there was little indication of the primacy of risk assessment as necessary to the 'simple' management of 
individuals within new penality thinking (Feeley and Simon 1992). Sixty-eight per cent of our respondents who replied to the question $(n=937)$ felt that the probation service was underpinned by an agreed set of values and that it was unique for that reason (67\%). These values were outlined by those adding qualitative comments $(n=725)$. As we commented in our earlier study:

'...... analysis showed the following words and phrases appearing most often: 'people can change' (mentioned in 22\% of responses); 'committed to offenders' (20\%); 'provide a service' (19\%); protect the public' (19\%); a number of other responses with below 10\% of mentions: 'treating people with respect'; 'being professional'; 'honesty'; operating 'care and control'; 'social work values'.'

(XXX 2015: 23)

This exemplifies respondents who believe that they are part of 'collective of professionals doing an important job well' (Ugelvik 2016: 226). The survey included a question on whether respondents felt that their own and the values of the service had come under pressure recently and why this might be. Responses to these questions relate to selflegitimacy because they reveal whether the values that respondents feel that the service should have and perhaps did have, had changed in a way that might affect their continuing level of commitment to the organisation and an internalisation of its values. It is important at this point to note that the comments about the pressure upon service values related to a period prior to the TR proposals. 
Indeed, there was no harking back to any supposed 'golden age'; clearly respondents felt that the values of the organisation (and hence possibly their commitment to it) had been under pressure for some time and that TR was just the latest, albeit most radical, reason for this pressure. To exemplify the point that pressure on probation values is not new, Mawby and Worrall (2013) noted that probation practitioners over a period prior to TR had been carrying out 'edge-work', i.e. negotiating in practice terms a policy environment in tension with their own values and what they felt their organisation's values were or should have been. Additionally, in our survey, respondents spoke about values in a range of ways, from theoretical notions, to ideas linked more directly to probation practice, and about the impact of a divided, partly-privatised service on the longevity of a certain type of probation values.

Comments were made about the erosion of probation values over time, mainly as a result of government initiatives intended to redirect the service to new agendas. This had also resulted in the growing distance (in the view of some respondents) between practitioners and managers both in terms of values and practice, although this was not recognised or shared by the smaller number of managers who completed the survey $(n=181)$. Only one manager made reference to a difference in values between practitioners and managers and it may be significant that $s /$ he refers to senior management.

'I think the front line staff relate to supporting the offender, protecting the public and reducing reoffending, but I feel that this has been lost by senior management and those governing Probation. The drive seems less about doing the job and more about targets, ticking boxes and data recording.' (Practitioner) 
'Gone is the importance of actually helping, assisting and befriending - and in has come "managing offenders" with ticking the right boxes and completing the case records and assessments more important than actual working with offenders.' (Practitioner)

'The values of senior management are not the values of practitioners.' (Manager)

There was also some references to new recruits entering the service with different values and expectations.

'Over time and with a move towards 'enforcement' new staff have come into the Service with very different values and expectations - they are not mine.'

It has been argued that in the past, probation practitioners had been able to resist policy changes perceived as managerial and punitive by 'adaptively and strategically interpreting, evaluating, [and] reconstructing' central priorities (Cheliotis 2006: 324). In that way, practitioners acknowledged differences between corporate and practitioner views of quality service provision and were able to remain true to their perceptions of quality service provision and thus, their values (Robinson et al. 2014: 135). In some instances, this was done with the quiet acceptance of management (Grant 2016: 759). However, the divide between management and practitioners noted in the comments, as well as an increasing sense of new recruits not sharing the 'old' value base is a clear indicator of a lack of trust amongst some practitioners in their supervisors and their colleagues (see also Deering 2011). This raises questions about the extent to which practitioners feel supported by their organisation and 
feel a sense of shared values not only with their colleagues but the organisation as a whole a core component of self-legitimacy (Bradford and Quinton 2014: 1028).

It was clear that whilst the underpinning values of the service were fundamental to perceived legitimacy, so was position of probation work within the public sector. Seventy-one per cent of respondents felt that it mattered who did probation work, regardless of whether it was done well. This was seen as a matter of principle, from the point of view of the state being the legitimate vehicle for administering (state-imposed) punishment and also that profits should not be made from punishment and hence, indirectly, from the commission of crime itself. More pragmatically, respondents felt that private operators would be ultimately and inevitably responsible to their shareholders and thus, by definition, unable to carry out probation work based on the same set of fundamental values of having faith in people's ability to change and contributing to a fairer society.

Comments were also made about the likely effectiveness of commissioning agencies outside the public sector to deliver probation services, and it is clear that respondents felt that the perceived - external and internal - legitimacy of probation work would be affected by its transfer to the private sector. Our respondents felt the importance of being part of the public sector and not involved in the pursuit of profit was at the heart of the value system that the probation service should have and, in this way the TR changes have potentially had a significant impact upon self-legitimacy. 
'Justice is a public good. Justice is done by the state and through communities, and so anyone involved in this process should be responsible to the communities and not operating for financial reasons.'

'Offenders are amongst the most deprived sections of society and it is immoral for anyone to make a profit out of them. There is also a conflict of interest for the private sector in that if they succeed in reducing reoffending they might deprive themselves of work-does anyone really think that this is realistic?'

Furthermore, respondents also felt that their relationships with those under supervision were liable to be adversely affected, due to the perceptions of the service that respondents felt their supervisees would have. These comments related to internal legitimacy, principles of role models for those subject to supervision, respect, and relationship building.

'We know that in terms of desistance, it's the relationship with the probation officer that eventually facilitates real change. How can organisations like A4E or Sodexo have the kind of 'values in practice' (not on a bid webpage) that service users can identify with and more importantly, work with?'

'Neither punishment nor protecting the public should be for commercial gain as this can then be the focus and lead to more discrimination against vulnerable adults. A lot 
of offenders have mental health issues and have suffered abuse and/or discrimination they have a distrust of those in authority. In order to work well the focus needs to be on offender engagement not on profit.'

We asked direct questions about the views of respondents' current supervisees as well as opinions about future supervisee behaviour. Seventy-six per cent of our respondents suggested that their current supervisees had expressed concerns about supervision by a private or third sector organisations; and virtually all (99\%) respondents felt that internal legitimacy - i.e. the extent to which supervises see probation practice as legitimate - was essential for compliance. Accordingly, practitioners (69\%) expressed a concern that compliance would suffer in organisational arrangements involving private/third sector organisations and were convinced that their supervisees would be less likely to comply with their orders in the future. There was a clear assumption that supervisees would take a similar view of the legitimacy of any organisation responsible for their supervision.

In the context of probation, there is little evidence to predict how those under the supervision of the NPS and CRCs will respond to the change in ownership and whether it will matter to them in terms of compliance with their orders and licence arrangements. Jackson et al. (2010) argue that the legitimacy of specific prison regimes is affected by a number of factors including the perceived motivations of those administering the punishment. McNeill and Robinson (2013) discussed whether privatisation may place in jeopardy the professional relationship between supervisees and probation staff and suggested that effective probation work is premised on the nature of the professional relationship between them (McNeill and Robinson 2013, 122). This relationship then becomes a site for legitimation activity rather 
than a relationship were legitimacy is regarded - at least by one party - as a given. However, in contrast, research by User Voice (2015) on probation supervisees' views of TR supports the notion that it is the relationship between probation staff and supervisee that matters rather than service structures or questions of ownership. Similarly, Hucklesby (2013: 148) who explored factors explaining compliance with electronic monitoring of curfews, found that none of those monitored 'questioned the legitimacy of monitoring officers as representatives of a private company'. Thus, in general terms the relatively limited literature on the subject gives a mixed and unclear picture about whether 'ownership' is linked to internal legitimacy.

Reponses to our survey highlighted concerns about the privatisation of part of the probation service. However, the prospect of working in a privatised service was not an issue for those about to join the NPS and we expected that such respondents would be less concerned about their future. Nevertheless, overall respondents felt that prospects were poor for both organisations in terms of professional practice, but also for staff morale and the relationship and communication between the NPS and the CRCs. These were seen as probable outcomes within the NPS, as well as the CRCs. Trends that had already been identified within probation trusts were felt likely to be exacerbated and the following were mentioned: managerialism, 'tick box' auditing, lack of interest in quality and the 'management of offenders' as opposed to more rehabilitative efforts. Respondents described a consequent lack of staff morale at the time of the changes and expected this to worsen as a result of the split.

'All those who can are therefore leaving. Those who can't leave now are planning how to exit from probation as quickly as possible. If the country were not in such an 
economic downturn, I think the exodus of staff would already have paralysed the service nationally'

'I think it used to be [underpinned by shared values] but gone are the days of advise, assist and befriend. I think colleagues and management are working to different values. My main aim is to keep my head above water and to make sure I look after my own health and stress levels. It is difficult to focus fully on much else.'

In addition, there was a relative lack of enthusiasm for the prospect of working for the NPS (certainly when compared to the status quo) despite its place within the public sector. Furthermore the prospects for the CRCs were seen as even worse, including the negative professional impact caused by what was predicted would be less than ideal relations between the two organisations. Potential negatives about working within the NPS were: a sole focus on high risk of harm cases leading to 'burn-out' (see Phillips et al 2016 below) and a narrowing of professional experience and hence expertise; shared understandings between NPS and CRC staff about notions of risk etc. However, greater concerns were expressed about working within the CRCs in terms of: being seen as inferior and providing a 'second class service'; a focus on working only with lower risk of harm individuals. There were also concerns commonly expressed about a lack of communication between the NPS and CRCs that would have an inevitable impact upon practice. 
'Only high risk MAPPA and sex offender work will be very demanding and stressful. It will become more bureaucratic as [part of the] Civil Service. The caseload is increasing and the loss of lower risk individuals and especially female offenders will deskill staff.'

'The mix of category of risk cases was always very healthy and helpful. I am worried that no risk assessment has been done with regards to staff's health and well-being in dealing with non-stop high risk stuff.'

'No clarity about what the role is but it feels as if all the responsibility will be placed upon the shoulders of NPS staff. There will be constant pressure to get assessments right, these will come back to bite them when anything goes wrong in the CRC e.g. a SFO. The job will be a relentless round of risk assessment and MAPPA meetings and supervising risking individuals. There will be no down time with low/medium risk individuals who just need a bit of guidance on sorting themselves out. Instead it will be just worry, worry, worry.'

Indeed even at the time (shortly before the split in June 2014) the effects were being seen in terms of a deterioration in relations between some staff. These emerging divisions between NPS and CRCs were confirmed twelve months later by Kirton and Guillaume (2015, 25-27) who noted that probation staff not only made distinctions between NPS and CRCs but also that different CRC cultures were beginning to form. 
'In all honesty, the relationship in my office and those of colleagues I know around the country, between CRC and NPS delegated staff is deteriorating rapidly and the change has not yet occurred'.

'I think professional respect will be an issue, as those officers going to the CRC are feeling de-skilled. Having worked for the Prison Service, I am very aware of the lack of respect from both staff and prisoners towards private sector staff - they are not deemed to be "real" prison officers.'

Finally, these negative changes were seen as being partly the result of ministerial and MoJ behaviour prior to the split, whether inadvertent, naively optimistic or more perniciously deliberate. This suggests concern about a fragmentation of the workforce undermining any sense of a collective of professionals working to a common set of core values.

'The fact that the Minister keeps referring to the NPS as a team of specialist staff [is not helpful] when in fact the split has come about through a very random process for staff and the same experienced staff will be in the CRC, some of which will be better qualified and skilled than those in the NPS.'

'Through the whole process of the split the staff who have been allocated to the CRC have been made to feel that they will not be as valued as their colleagues in the NPS. This will and has created negative feelings which will not help working relationships.' 


\section{Fear of the unknown or predictive power?}

It is reasonable to suggest that those who responded to our survey were simply frustrated with changes clashing with their political views. In addition, those who are caught in the liminal, the in-between stage, may have expressed their uncertainty about the future when given the opportunity. Unfortunately however, some of the gloomy predictions made above appear to have materialised, at least in the short to medium term and a number of recent studies raise issues that, at the very least, can be taken to suggest that the impact upon self-legitimacy is likely to be significant and perhaps long-lasting.

For example, in a recent Probation Inspectorate report (HMIP 2016a: 4) on probation services in Durham, the Chief Inspector of Probation highlighted consistent problems with quality assurance in CRCs and noted that the work undertaken was 'insufficiently focused on reducing reoffending and protecting the public'. She also noted staff morale in Durham as good, 'in contrast to most other areas', This highlightsing the persistence of the apparent negative impact of Transforming Rehabilitation on probation staff morale two years after the split. Durham does appear to have been something of an exception,

seemingly because it had a long tradition prior to TR of a stable workface and low staff turnover. This had survived TR and at the time of the inspection most of the staff had been employed by the trust and 'retained a strong sense of loyalty and attachment' to their new employer (HMIP 2016: 16). . This sisto 
Additionally, in a report looking at the 'value for money' provided by the TR changes, the National Audit Office (NAO) found that (NAO 2016: 5-11) whilst 77 per cent of a sample of supervisees from four surveyed CRCs had noticed no overall change in services provided there was evidence of some level of mistrust between staff of the NPS and CRCs, high workloads in both the NPS and CRCs had reduced levels of supervision and training and that CRCs were being paid for outputs not outcomes and therefore had less incentive to be innovative.

The HMIP's last of five reports focusing on the impact of TR (HMIP 2016c) looked at practice in the NPS and CRCs in terms of services to the court, risk assessment and management and sentence planning, the quality and timeliness of supervision and the supervision of staff. The HMIP report concluded that reports to court were of variable quality and that, unsurprisingly, written reports, prepared after an adjournment were better than oral reports prepared at short notice. Court staff sometimes felt insufficiently prepared and trained and as an overall result, risk assessments were variable, including where risk of serious harm was a possibility. This in turn led to allocation of cases to either the CRC or NPS not being always based on the best and most thorough information (2016c: 5). In terms of supervision, within the CRCs a variable situation was outlined in terms of the allocation of cases, the completion of sentence plans that properly engaged the supervisee and the lack of focus and progress on issues such as accommodation, employment and finances. Compliance was managed well, although breach rates were low as the financial impact upon the CRC was regarded as a disincentive to breach proceedings, although the report concluded that this encouraged practitioners to work hard at securing compliance (2016c: 6). As regards the NPS, similarly a mixed situation was found, with evidence of good individual practice and an overall performance somewhat better than the CRCs, although concern was expressed about some 
risk of harm assessments and management plans. In both CRCs and NPS, middle managers were seen as often struggling to provide consistent supervision and support to staff given their overall workloads (2016c: 6-7).

The latest HMIP (2016b) report on Through the Gate Resettlement Services assessed the impact of TR on support for prisoners on short-term sentences and its conclusions suggested that 'the good intentions' of the TR reforms which extended supervision to short-term prisoners including those with complex and multiple needs 'have not yet been realised'. The report was highly critical and included a long list of recommendations.

Furthermore, recent research looking at both the NPS and CRCs also has discussed implications of the split for perceptions of legitimacy of both organisations. Phillips et al (2016) found that working only with high risk supervisees appeared to have a variable impact upon NPS practitioners, but that the change was seen as raising overall levels of stress. The authors regarded the situation as 'untenable in the long term' (Phillips et al 2016: 189) unless the NPS can provide a tiering system within high risk, offer staff better support, and cut case and work loads overall. In an example from practice within a CRC, McDermott (2016) considered the possibilites for 'agile working', considering the possibilities for innovation and varied approaches and how this might affect the building of good relationships between supervisees and supervisors. Her conclusion was that due to the operational prioroties of the CRC, practitioners had seen 'a lack of facilities and resources, increased workloads, absence of IT support or incompatibility between space and caseloads or staffing' (McDermott 2016: 199). 
Finally, a further element to be considered would be the potential for the different treatment in terms of supervision of lower and higher risk individuals. Previous studies have shown that whilst practitioners recognised the need to allocate sufficient resources to the higher risk of harm individual, they also felt that this should not mean the diminution of work the with lower risk of harm, as this group is often of a higher risk of re-offending and have significant needs (Deering 2011). However, since the split, there is some indication that lower risk of harm individuals are likely to be offered a more 'light touch' supervision, with at least some CRCs having already indicated that in order to reduce costs, some supervisees will move to a 'reporting only' regime using biometric technologies (Travis 2015). At the very least, it seems likely that should such a situation become commonplace, practitioners within the CRCS will regard their role as increasingly less legitimate, because, as a number of studies (e.g. Annison et al. 2008; Deering 2011; Mawby and Worrall 2013) have shown that practitioners consistently see their role as rehabilitative and not simply as just the management of individuals.

Other studies throw some further light on these issues. For example, Dominey (2016) argues that TR is likely to damage relationships between practitioners and those on supervision and thus pose a threat to the desistance process. Moreover, she identifies a negative impact upon inter-agency working, particularly between the CRCs and the courts and the CRCs and the NPS, findings echoed in the NAO (2016) and HMIP (2016) reports mentioned above. Alongside this, increased workloads and moves towards 'reporting only' models of supervision have, in her view, made it possible that community sentences face a 'more fragmented and less legitimate future' (Dominey 2016: 141). In a study looking at the 
impact on individuals on an intensive community order of being classified as 'high risk' and moved to the NPS, Kay (2016) argued that this had a negative impact upon perceptions of self amongst supervisees, but also, in some cases caused them to question the competence of former (now CRC) supervisors. Overall, the impact was seen as having the potential to 'disrupt the desistance process' (Kay 2016: 167).

\section{Conclusion}

The question of perceptual legitimacy, internal, external, and self-legitimacy has become a core site of debate for probation. The data above reveal a range of views on the impact of TR on the various aspects of legitimacy. Respondents were concerned about the impact on internal legitimacy and levels of offender compliance. There were also comments relevant to Bradford and Quinton's (2014) conditions for self-legitimacy, namely levels of attachment to the new organisations; the internalisation of organisational goals; a sense of being supported by the organisation; and a belief that probation staff in both the CRCs and the NPS remain legitimate holders of authority.

Respondents questioned the ethics of the new organisations and were frustrated by a perception of an erosion of common organisational values. This is evident in comments that the senior and middle management of the old service had been complicit in moving away from a set of values that focused on rehabilitation, 'help' in a broad sense, within an overall system of accountability to the court. These had been replaced by a managerialist approach that eschewed quality for outputs and the attainment of targets. There is clear evidence that most of sample felt that the probation values had already come under pressure and been 
compromised before TR, but that there was a sense that this would be exacerbated by the structural split and have a negative effect on probation staff, probations supervisees, and ultimately, the public.

In terms of feeling that they may have a special place in society, probation practitioners have perhaps never really felt such a concept applied as much to them as to the police. Clearly the latter have a much higher public profile and the probation service has long had a very low public profile with subsequent low levels of public understanding about 'the job' (Mawby and Worrall 2013; Roberts and Hough 2005). As a result, perhaps this particular element of Bradford and Quinton's definition of self-legitimacy is less relevant to probation, but the discussion above of the fears of practitioners about the emergence of a two-tier service in terms of the relative prestige attached to the CRCs and the NPS and the concomitant deterioration of relations between the two organisations may well have a deleterious impact upon public image. However, if respondents come to feel that the service provided to supervisees is not what it had previously been, this may have a negative effect on their feelings of authority, as this is presumably based, in part at least, on them feeling that they are providing an appropriate service.

There is a strong sense that the split of the probation service into the NPS and the CRC has had an effect beyond purely structural alterations. Some probation staff's sense of self-legitimacy appears to have been severely disrupted and there is a conviction that the concern of the legitimacy of probation practice will be shared by those under probation supervision and affect levels of compliance with court orders. These narratives may well be a reflection of the sense of liminality, of being in-between the old and the new, and in due 
course, familiar self-legitimation narratives may be revived. In an interesting development that seems to express a concern for professional standards, the Probation Institute is working to attain the status of a Regulatory Body to assert the importance of professional standards and competence (Probation Institute 2016). Such an approach, seeking as it does to reinforce probation's professionalism may be seen as part of a legitimation narrative.

However, unsurprisingly there is evidence to suggest that practice is already changing and that probation provision is becoming increasingly fragmented with clear differences emerging between NPS and CRCs (HMIP 2016a), different CRCs owners, and different regions. It will take some time to assess the effects of such fragmentation for offender populations and questions of equity of service provision, impact on diverse populations - women, ethnic minorities, young adults - re-offending rates, and desistance processes. What is already clear is that considerable damage has been done to some individual probation staff's sense of being a member of a 'collective of professionals doing an important job well' (Ugelvik 2016: 226).

\section{References:}

Annison, J., Eadie, T. and Knight, C. (2008). 'People first: probation officer perspectives on probation work'. Probation Journal, 55(3): 259-272.

Beetham, D. (1991). The legitimation of power. London: Macmillan. 
Bottoms, A. (2003). 'Theoretical reflections on the evaluation of a penal policy initiative'. In L. Zedner and A. Ashworth (Eds.) The criminological foundations of penal policy. Oxford: OUP.

Bradford, B. and Quinton, P. (2014) 'Self-legitimacy, police culture and support for democratic policing in an English Constabulary'. British Journal of Criminology, 54: 1023-1046.

Cheliotis, L.K. (2006) 'How Iron is the Iron Cage of New Penology?: The Role of Human Agency in the Implementation of Criminal Justice Policy', Punishment and Society, 8(3): 313340.Crawford, A., and Hucklesby, A. (Eds.) (2013). Legitimacy and compliance in criminal justice. Abingdon: Routledge

Crewe, B. and Liebling, A. (2012). 'Insider views of private sector competition'. In HelyarCardwell, V. (ed.) Delivering justice: the role of the public, private and voluntary sectors in the prison system. Criminal Justice Alliance Publications.

Deering, J. (2011). Probation practice and the new penology: practitioner reflections. Aldershot: Ashgate.

Dominey, J. (2016). 'Fragmenting probation: recommendations from research'. Probation Journal, 63(2): 136-143.

Feeley, M. and Simon, J. (1992). 'The New Penology: Notes on the Emerging Strategy for Corrections'. Criminology, 30(4): 449-475. 
Genders, E. (2002). 'Legitimacy, Accountability and Private Prisons'. Punishment and Society, 4(3): 285-303.

Grant, S. (2016). 'Constructing the durable penal agent: Tracing the development of habitus within English probation officers and Scottish criminal justice social workers'. British Journal of Criminology, 56: 750-768.

Hough, M., Jackson, J., Bradford, B., Myhill, A. and Quinton, P., (2010). 'Procedural justice, trust and institutional legitimacy'. Policing: a Journal of Policy and Practice, (3): 203210.

HMIP (2016a). Quality and Impact inspection: The effectiveness of probation work in Durham. https://www.justiceinspectorates.gov.uk/hmiprobation/wpcontent/uploads/sites/5/2016/08/Durham-QI-report.pdf

HMIP (2016b). An Inspection of Through the Gate Resettlement Services for Short-term prisoners. http://www.justiceinspectorates.gov.uk/cjji/wpcontent/uploads/sites/2/2016/09/Through-the-Gate.pdf

HMIP (2016c). Transforming Rehabilitation. Early Implementation 5. London.

Jackson, J., Tyler, T.R., Bradford, B., Taylor, D. and Shiner, M. (2010). 'Legitimacy and procedural justice in prisons'. Prison Service Journal, (191): 4-10. 
Kay, C. (2016). 'Good cop, bad cop, both? Examining the implications of risk based allocation on the desistance narratives of intensive probationers'. Probation Journal, 63(2): 162168.

Kirton, G. and Guillaume, C. (2015). Employment Relations and Working Conditions in Probation after Transforming Rehabilitation. Accessed: https://www.napo.org.uk/advice-and-resource; 9/12/2016.

Mawby, R.C. and Worrall, A. (2013). Doing Probation Work: identity in a criminal justice occupation. London: Routledge.

McDermott, S. (2016). 'Probation without boundaries? 'Agile working' in the Community Rehabilitation Company 'transformed' landscape'. Probation Journal, 63(2): 193-201.

Ministry of Justice (2016). Civil Service People Survey 2016: The National Probation Service. Accessed:

https://www.gov.uk/government/uploads/system/uploads/attachment data/file/57 3656/nps-people-survery-results-2016.pdf; 9/12/2016

Ministry of Justice (2014). Workforce Information Summary Report, Q4 2013/14. Accessed: https://www.gov.uk/government/uploads/system/uploads/attachment_data/file/31 5043/Probation-Service-Workforce-Information-Summary-Report-Q4-2013-14.Pdf: https://www.gov.uk/government/publications/probation-service-quarterly-reports20132014; 04/11/2014. 
Ministry of Justice (2013). Transforming Rehabilitation: a revolution in the way we manage offenders. London: Ministry of Justice.

Murphy, K., Bradford, B., and Jackson, J. (2015). Motivating compliance behaviour among offenders: Procedural Justice or Deterrence? Criminal Justice and Behaviour. Online: November 3, 2015, doi: 10.1177/0093854815611166.

Napo (2006). Probation values: commitment to best practice. London: Napo.

National Audit Office (2016). Transforming Rehabilitation. London: NAO.

Nellis, M. (2002).'Probation, partnerships and civil society'. In D. Ward, J. Scott and M. Lacey, (eds.). Probation: working for justice. Oxford: Oxford University Press.

Nellis, M. and Gelsthorpe, L. (2003).'Human rights and the probation values debate'. In W. Chui and M. Nellis, (eds.). Moving probation forward. Harlow: Pearson.

Phillips, J., Westaby, C. \& Fowler, A. (2016). "It's relentless'. The impact of working primarily with high-risk offenders'. Probation Journal, 63(2): 182-192.

Probation Institute (2016). CEO Blog September 2016. http://probation-institute.org/ceoblog-september-2016/ 
Roberts, J. and Hough, M. (2005). Understanding public attitudes to criminal justice. Maidenhead: Open University Press.

Robinson, G., Priede, C., Farrall, S., Shapland, J. And Mcneill, F. 2014. Understanding 'Quality' In Probation Practice: Frontline Perspectives In England And Wales. Criminology And Criminal Justice, 14(2), 123-142.

Robinson, G., Burke, L. \& Millings, M. (2016). 'Criminal justice identities in transition: the case of devolved probation services in England and Wales'. British Journal of Criminology, 56: 161-178.

Robinson, G. and McNeill, F. (2004).'Purposes matter: examining the 'ends' of probation'. In G. Mair, (ed.). What matters in probation. Cullompton: Willan.

Sunshine, J. and Tyler, T.R. (2003). 'The role of procedural justice and legitimacy in shaping public support for policing'. Law and Society Review, 37(3): 513-548.

Travis, A. (2015) Probation officers face redundancy with plans to replace them by machines. The Guardian.

Ugelvik, T. (2016). Techniques of legitimation: The narrative construction of legitimacy among immigration detention officers. Crime, Media, Culture, Vol 12(2), 215-232.

Uservoice (2015). Transforming Rehabilitation. The operational model from the service user's perspective. 
content/uploads/2016/04/\%E2\%80\%9CTransforming-Rehabilitation\%E2\%80\%9D-

The-operational-model-from-the-service-user\%E2\%80\%99s-perspective-PDF.pdf

Van Craen, M. (2015). Understanding police officers' trust or trustworthy behaviour: A work relations framework. European Journal of Criminology.

Williams, B (1995). Probation Values. London: Venture Press.

Worrall, A. and Mawby, R. (2014). Probation worker cultures and relationships with

offenders. Probation Journal, Vol 61(4), 346-357.

\footnotetext{
i For convenience, we continue to call practitioner staff of the National Probation Service and the Community Rehabilitation Companies 'probation practitioners'

ii Only 25\% felt that pay reflects performance; and 23\% were satisfied with benefits.

iii As of 31 March 2014, 16,110 FTE staff were employed by the Probation Service (Ministry of Justice 2014).
} 